\title{
$O$ autocuidado sob a perspectiva da Terapia Ocupacional: análise da produção científica
}

\author{
Regina Célia Titotto Castanharo ${ }^{\mathrm{a}}$, Lillian Daisy Gonçalves Wolff
}

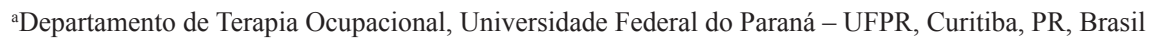 \\ bPrograma de Pós-Graduação em Enfermagem, Universidade Federal do Paraná - UFPR, Curitiba, PR, Brasil
}

\begin{abstract}
Resumo: Estudo descritivo-exploratório que buscou explicitar como o autocuidado tem sido abordado pela Terapia Ocupacional (TO). Como fontes de dados utilizaram-se o LILACS, o SciELO e os formulários avançados dos periódicos nacionais de Terapia Ocupacional. Selecionaram-se 12 artigos publicados entre 1994-2012 por terapeutas ocupacionais, contendo os termos terapia ocupacional, autocuidado, atividades cotidianas ou de vida diária como palavras-chave no resumo ou texto completo. A revisão integrativa e análise temática dos dados evidenciaram as categorias: autocuidado e atividades de vida diária; autonomia e independência para o autocuidado; intervenção do terapeuta ocupacional para favorecimento do autocuidado pelo indivíduo. Os resultados apresentam diferentes dimensões do autocuidado, associadas à autonomia e independência do indivíduo e às práticas profissionais privativas e interdisciplinares da TO. A intervenção nessa área dirige-se ao desempenho humano nos ciclos de vida, frente a situações de vulnerabilidade, como doenças e exclusão social. Utilizam-se adaptações, modificações, recursos de tecnologia assistiva e/ou reabilitação funcional para promover independência do indivíduo, favorecendo a autonomia e retomada de rotinas. Observam-se convergências entre concepções sobre autocuidado na produção científica da TO e o referencial de Orem (1971-2001). Em geral, profissionais de saúde podem auferir benefícios da sistematização do conhecimento que fundamenta sua prática quando o articulam, também, com conhecimentos já sistematizados por outras áreas.
\end{abstract}

Palavras-chave: Terapia ocupacional, Autocuidado, Atividades Cotidianas.

\section{Self-care under the perspective of Occupational Therapy: analysis of scientific production}

\begin{abstract}
This is an exploratory descriptive study aiming to explain how self-care has been addressed by Occupational Therapy (OT). Data collection was carried out by consulting LILACS, SciELO databases and national journals of Occupational Therapy. From 1994 to 2012, twelve articles published by occupational therapists were selected considering the following keywords on abstracts or full texts: occupational therapy, self-care, daily activities or daily life activities. The results were submitted to integrative review and thematic analysis. The categories evidenced were self-care and activities of daily life; autonomy and independence for self-care; and intervention of OT favoring self-care by the individual. The results showed different dimensions of self-care when associated with the individual and private autonomy as well as with professional interdisciplinary practices of OT. The intervention in this area is directed to human performance in the cycles of life, faced with situations of vulnerability, such as disease and social exclusion. Adaptations, modifications, assistive technology resources and/or functional rehabilitation are used to promote the independence of individuals, favoring autonomy and recovery routines. We observed similarities between the conceptions of self-care found in the scientific production of OT and in the Orem's concepts (1971-2001). In general, health professionals can achieve benefits to the systematization of knowledge that underlie their practice when they articulate them with the knowledge systematized by other areas.
\end{abstract}

Keywords: Occupational Therapy, Self-Care, Daily Activities.

Autor para correspondência: Regina Célia Titotto Castanharo, Universidade Federal do Paraná, Campus Botânico, Av. Lothário Meissner, 632 Jardim Botânico, CEP 80210-170, Curitiba, PR, Brasil, e-mail: prof.retitotto@ufpr.br

Recebido em 21/5/2012; $1^{\text {a }}$ Revisão em 16/8/2012; $2^{a}$ Revisão em 21/9/2012; $3^{\text {a }}$ Revisão em 4/10/2012; Aceito em 15/10/2012. 


\section{Introdução}

Em organizaçōes de Saúde, o atendimento a necessidades individuais ou coletivas é realizado por diferentes profissionais. No caso da prática profissional de terapeutas ocupacionais, o foco é o desempenho ocupacional, considerando o autocuidado na perspectiva coletiva de tarefas básicas do indivíduo em relação ao cuidado pessoal (HASSELKUS, 2008). Assim, os terapeutas ocupacionais consideram que as habilidades do indivíduo para tarefas básicas se desenvolvem e mudam ao longo da vida, portanto buscam promover a sua própria independência e autonomia para realizá-las.

Por sua vez, os enfermeiros realizam cuidados que visam à manutenção da vida, tais como de higiene, mobilização, hidratação, eliminaçóes, aqueles que visam à cura, envolvendo prevenção, promoção da saúde, tratamento e recuperação e, ainda, ao preparo do indivíduo para o autocuidado. $\mathrm{O}$ conceito de autocuidado, na Enfermagem, foi sistematizado por Dorothea Orem (1971-2001), enfermeira estadunidense, docente do Departament of Health, Education and Welfare - Washington - DC, por meio da Teoria do Déficit de Autocuidados - Self-care Deficit Nursing Theory - SCDNT. Tal conceito é concebido como

[...] função reguladora humana que é uma ação deliberada para suprir ou garantir o fornecimento dos materiais necessários para continuar a vida, o crescimento e o desenvolvimento e manutençẫo da integridade humana [...] (McEWEN; WILLS, 2009, p. 170).

A autora acrescenta que o cuidado que o homem é capaz de prestar a si próprio é aprendido ao longo do seu desenvolvimento e amadurecimento.

Segundo Torres, Davim e Nóbrega (1999), são três os requisitos de autocuidado ou exigências apresentados por Orem: universais, de desenvolvimento e de desvio de saúde. Os universais estáo ligados aos processos de vida e à manutenção da integridade da estrutura e funcionamento humanos, tendo como exemplo as atividades cotidianas. Os requisitos de desenvolvimento estão associados aos processos particularizados do desenvolvimento, tendo como exemplo a adaptação a um novo trabalho. Os de desvio de saúde, segundo os autores acima citados, são exigidos em condiçôes de doença, ou podem ser consequência de medidas médicas exigidas para diagnosticar e corrigir uma condição.
Para Orem, o autocuidado é a prática de atividades que o indivíduo inicia e executa em seu próprio benefício, na manutenção da vida, da saúde e do bem-estar. (TORRES; DAVIM; NÓBREGA, 1999, p. 48).

A Teoria de Orem é amplamente utilizada por enfermeiros para estruturar os atendimentos clínicos, como em estudos, apresentando-se como estrutura conceitual ou como fonte de pesquisas (McEWEN; WILLS, 2009).

Considerando a Terapia Ocupacional, no período compreendido entre 1994 e 2002, os terapeutas ocupacionais utilizavam o termo autocuidado fazendo referência a uma das áreas do desempenho ocupacional humano, de acordo com a Terminologia Uniforme da American Occupational Therapy Association (AOTA), de 1994. Todavia, foi publicado em 2002 o Novo Documento - Domínio e Processo (Occupational therapy association practice framework: domain and process) (AMERICAN..., 2002), integrante da terceira ediçâo da Terminologia Uniforme para a Terapia Ocupacional, no qual a área de desempenho autocuidado voltou a ser denominada atividades de vida diária (AVD). Essas sáo atividades orientadas ao cuidado do indivíduo para com o seu próprio corpo, como o banhar-se, controlar os esfíncteres etc.

Destaca-se que tanto a Enfermagem como a Terapia Ocupacional são profissóes com atuação junto a indivíduos e comunidade em prol do atendimento das suas necessidades de saúde. Para tanto, buscou-se estudar o significado do conceito autocuidado para ambas as profissóes, após o estudo da Teoria de Orem, durante o processo de titulação de uma das autoras no Mestrado de Enfermagem.

$\mathrm{Na}$ Enfermagem, o referencial de Orem fundamenta o autocuidado enquanto teoria. Todavia, na Terapia Ocupacional, ele é compreendido sob a óptica do desempenho ocupacional em diferentes áreas de ocupação do indivíduo. Constata-se, na prática de ambas as profissōes, que seus profissionais atuam orientando e auxiliando o indivíduo a agir com independência e autonomia em atividades cotidianas, como também preocupam-se com o engajamento do indivíduo em seu autocuidado. Portanto, enunciou-se como objetivo de pesquisa: explicitar como o autocuidado tem sido abordado pela Terapia Ocupacional (TO).

\section{Método}

O estudo caracteriza-se como descritivo exploratório. Utilizou-se, como método de 
procedimento, a revisão integrativa (GANONG, 1987), contemplando seis etapas. Na primeira delas buscou-se o estabelecimento do problema, com a definição da questão norteadora da investigação, ou seja, como o autocuidado tem sido abordado pela TO. Na segunda etapa, que se refere à seleçáo da amostra, os seguintes critérios de inclusão da produção científica foram estabelecidos: artigos latino-americanos, publicados na língua portuguesa ou espanhola no período de 1994 a 2012 por terapeutas ocupacionais; incluídos na Biblioteca Virtual em Saúde - BVS, na base Literatura Latino-Americana e do Caribe em Ciências da Saúde - LILACS e no repositório de periódicos da Scientific Eletronic Library On-line - SciELO, como também nos formulários dos dois principais periódicos nacionais de Terapia Ocupacional - Revista de Terapia Ocupacional da Universidade de São Paulo - USP e Cadernos de Terapia Ocupacional da Universidade Federal de São Carlos - UFSCar -, contendo em seu resumo ou palavras-chave um dos descritores: terapia ocupacional, autocuidado, atividades cotidianas ou atividades de vida diária, a fim de correlacionar tais estudos ao conceito de autocuidado proposto por Orem.

O período entre 1994 e 2012 foi escolhido por contemplar a produção científica após a publicação da terceira edição da Terminologia Uniforme para a Terapia Ocupacional. Do mesmo modo, as bases eletrônicas e os periódicos nacionais de Terapia Ocupacional selecionados foram determinados pelo fato de apresentarem o maior número de publicaçóes na área da Terapia Ocupacional, na América Latina, visando entender como o conceito de autocuidado tem sido apresentado na produção de terapeutas ocupacionais, as possíveis correlaçôes com o conceito utilizado na Enfermagem e, por último, contribuir para o aprendizado acadêmico.

A seleção das publicaçôes iniciou-se mediante a leitura do título e resumo de cada artigo, de modo a avaliar se os critérios de inclusão estavam contemplados. A busca inicial nos resumos resultou em 14 publicaçôes. Na leitura dos textos completos, um artigo foi excluído por não se tratar de artigo produzido por terapeutas ocupacionais e outra publicação, por se tratar de resumo de dissertação de Mestrado, totalizando 12 artigos selecionados.

$\mathrm{Na}$ terceira e quarta etapas foi realizada a caracterização dos estudos e os dados foram sistematizados na Tabela 1, em que os artigos apresentam-se associados a códigos de identificação, constituídos da letra A e algarismos de 1 a 12.

Na quinta etapa, procedeu-se à análise temática dos artigos e à discussão de resultados. Inicialmente, realizou-se a leitura dos resumos de todos eles e do texto integral de dez deles. Houve impossibilidade de acesso ao texto original de dois artigos (A10 e A12), mas os resumos forneceram informaçóes para responder à questáo norteadora e, portanto, eles não foram excluídos da amostra. Na sexta etapa, referente à interpretação dos resultados, foram incluídas informaçóes para que o leitor examine, criticamente, as evidências levantadas e suas implicaçóes em relação ao objetivo da pesquisa.

A seguir, em cada um dos artigos foram identificadas unidades de significado relativas à questão norteadora. Posteriomente, cada conjunto de unidades de significado semelhantes entre os artigos gerou um tema de análise. Os seguintes temas de análise foram contemplados: autocuidado e atividades de vida diária; autonomia e independência para o autocuidado; e intervenção do terapeuta ocupacional para favorecer o autocuidado pelo indivíduo.

\section{Resultados}

$\mathrm{Na}$ base de dados LILACS foram identificados dez artigos que corresponderam aos critérios de inclusão, sendo que três deles são internacionais. Dois artigos foram encontrados em publicação atualizada dos Cadernos de Terapia Ocupacional da UFSCar. A Tabela 1 apresenta a caracterização dos artigos, seu código, referência, tipo de estudo e palavras-chave. Houve repetição de um dos artigos (A5) no repositório SciELO, o qual não foi duplamente contabilizado.

$\mathrm{O}$ artigo $\mathrm{A} 1$ é um artigo de pesquisa qualitativa, fruto de projeto de extensão universitária da Universidade Federal de Minas Gerais - UFMG, o grupo em questão é denominado Grupo de Orientação e Autocuidado a Indivíduos Acometidos por Doenças Crônicas. Os autores contextualizam a análise e interpretação dos significados da modalidade grupal utilizada por terapeutas ocupacionais na atenção a doentes crônicos e referem os diferentes significados que os participantes atribuíram ao grupo, destacando-o como espaço de socialização, lazer e cuidado.

Em A2, o artigo intitulado Avaliação do nível de independência nas atividades de vida diária da criança com paralisia cerebral: Um estudo de caso, os autores apresentam um relato de experiência na atenção a crianças com paralisia cerebral utilizando o Inventário de Avaliação Pediátrica de Incapacidade - PEDI, objetivando avaliar o nível de independência dessas crianças nas atividades de vida diária antes e após a promoção do treino de atividades funcionais. A 


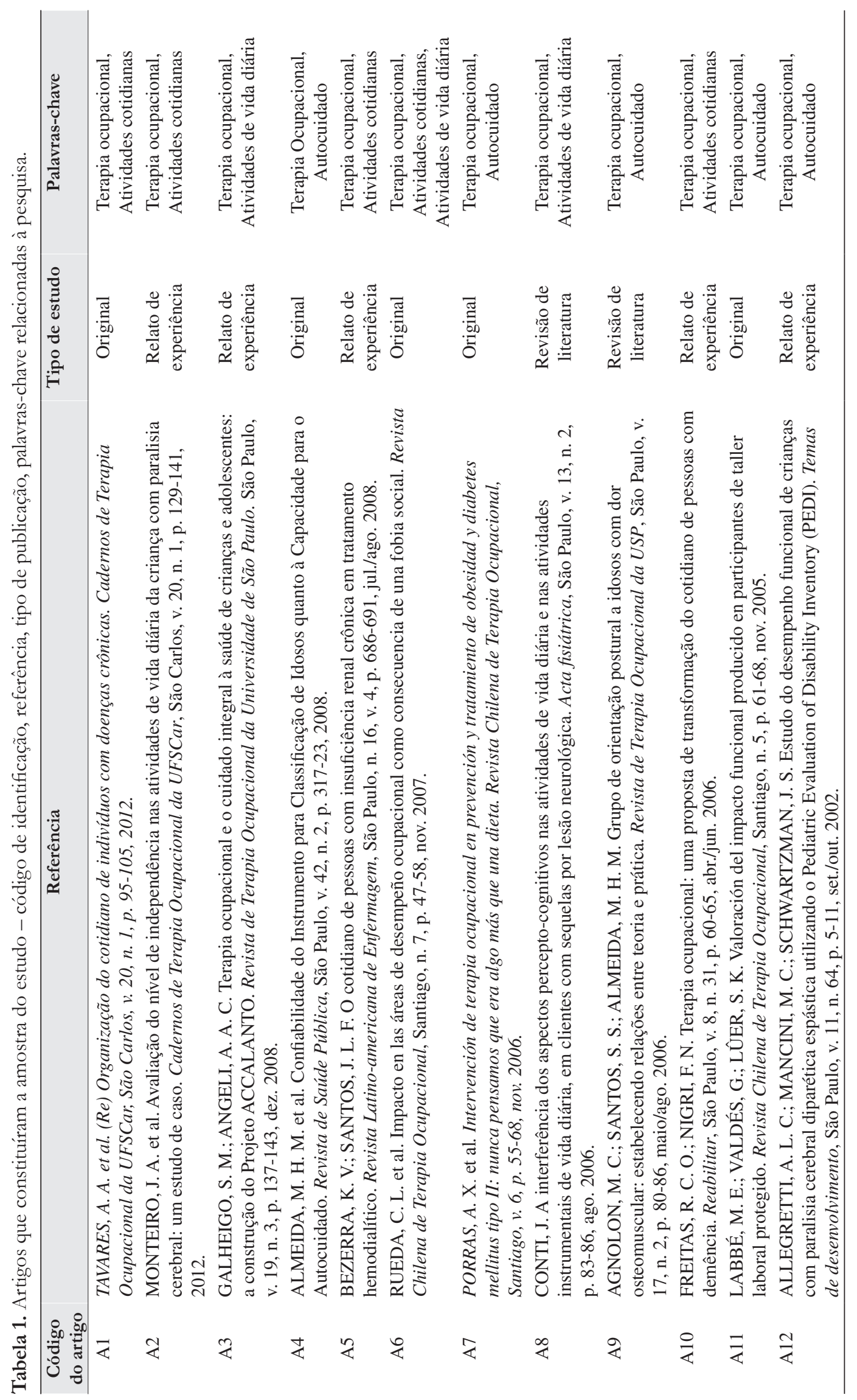


escala de autocuidado foi utilizada para avaliar as habilidades funcionais e a assistência do cuidador.

No artigo A3 os autores apresentam o Projeto Accalanto, desenvolvido como atividade de ensino, pesquisa e extensão universitária na área de Terapia Ocupacional focada na humanizaçáo do cuidado e proteção integral da infância e juventude. Destaca-se a atenção à população infanto-juvenil e seus familiares cuidadores diante de situaçôes de vulnerabilidade como adoecimento e hospitalização, sendo o autocuidado compreendido diante do processo de adoecimento.

No artigo A4, os autores avaliam a confiabilidade do Instrumento para Classificaçáo de Idosos quanto à Capacidade para o Autocuidado - CICAc, desenvolvido para auxiliar o terapeuta ocupacional na atenção a idosos em Unidades Básicas de Saúde. Trata-se de uma pesquisa cujos resultados evidenciam que tal instrumento possibilita a classificação sucinta e simplificada de idosos quanto à capacidade funcional para atividades básicas e instrumentais, bem como sua caracterizaçáo com referência aos demais aspectos do autocuidado. Constata-se, nessa publicação, que o termo autocuidado está referenciado de acordo com a terminologia da Terapia Ocupacional.

Em A5, os autores avaliam a percepção de pessoas com doença renal crônica e sua limitaçáo frente às atividades cotidianas utilizando o questionário Self Assesment of Occupational Functioning (SAOF).

$\mathrm{O}$ artigo A6 originou-se de uma pesquisa qualitativa em que os autores concluem que a prática da Terapia Ocupacional apresenta recursos instrumentais para a reestruturaçáo do cotidiano de pacientes com fobia social. Afirmam que esses contribuem também para o levantamento de informaçóes para as demais práticas na área da Saúde, com ênfase para a Enfermagem. Consideram a fobia social como fator de interferência em todas as áreas do desempenho humano e sugerem déficit no autocuidado desses pacientes, em específico em relação às AVDs. $\mathrm{O}$ artigo destaca a relação de colaboração interdisciplinar no atendimento a esses pacientes.

Os autores do artigo A7 descrevem uma experiência de intervenção terapêutica sob a modalidade grupal, com indivíduos portadores de doenças crônicas como a diabetes e a obesidade, em um Centro de Saúde da Família chileno. Não fazem referência direta ao autocuidado em seu resumo. Porém é possível correlacionar que, segundo a terminologia uniforme para a Terapia Ocupacional, o autocuidado está implícito nas atividades de vida diária.
$\mathrm{O}$ artigo A8, por sua vez, refere-se a três estudos de casos clínicos e tem, como objetivo, apresentar a reflexão sobre a interferência de aspectos perceptocognitivos nas atividades de vida diária e instrumental de vida diária diante de uma sequela neurológica como Acidente Vascular Encefálico - AVE.

Abordando a temática da prevenção da dor osteomuscular em idosos sob orientaçáo postural, o que propicia o desenvolvimento de habilidades de autocuidado, os autores do artigo A9 fundamentam-se no conhecimento da área da Terapia Ocupacional mas também associam-no aos pressupostos da Teoria do Autocuidado de Orem. Justificam a correlaçáo da Teoria do Autocuidado e o déficit de desempenho apresentado pela populaçáo idosa e destacam a prevenção da dor, sob a orientação do terapeuta ocupacional, em relação à postura e às habilidades para o autocuidado.

No artigo A10, os autores discutem a Terapia Ocupacional como uma profissão que possui um instrumental específico - as atividades cotidianas como meio de tratamento, que propiciam ao indivíduo com demência a estimulaçáo cognitiva para diminuir a sua dependência nas atividades de vida diária e em relação aos contextos domiciliar e social. Trata-se de um relato de experiência de terapeutas ocupacionais acerca da importância da estimulação de pessoas com déficit cognitivo - em especial, da memória -, a partir de suas rotinas.

$\mathrm{O}$ artigo A11 especifica a área de desempenho ocupacional trabalho e destaca a limitação que indivíduos acometidos por lesão medular enfrentam em sua rotina. A área de desempenho Atividades de Vida Diária é apenas citada como uma das que também sofrem limitaçóes.

O artigo A12 é um estudo sobre o desempenho funcional de crianças com paralisia cerebral diparética espástica e foi realizado no contexto escolar. O instrumento de avaliação utilizado foi o Pediatric Evaluation of Disability Inventory - PEDI. Tal instrumento avalia as habilidades de crianças para o autocuidado. No artigo, essas habilidades são sinalizadas como comprometidas pela patologia, dificultando a rotina das crianças no autocuidado pessoal e transferência, o que as torna dependentes de um cuidador.

\section{Discussão}

As três categorias que emergiram a partir da análise temática dos artigos foram: o autocuidado $\mathrm{e}$ atividades de vida diária; autonomia e independência para o autocuidado; e intervençáo do terapeuta 
ocupacional para favorecer o autocuidado pelo indivíduo, as quais geraram subcategorias.

\subsection{O autocuidado e atividades de vida diária}

\subsubsection{Subcategoria Atividades cotidianas}

$\mathrm{O}$ autocuidado refere-se a atividades cotidianas realizadas pelo indivíduo em seu próprio benefício, na manutenção da vida, da saúde e do bem-estar. Essas atividades são realizadas ao longo do ciclo de vida do indivíduo e podem modificar-se diante dos seus próprios processos de desenvolvimento e envelhecimento, ou de restriçóes, definitivas ou temporárias, originadas pelo adoecimento. Para alguns autores (TORRES; DAVIM; NÓBREGA, 1999), os propósitos dessas atividades são expressos por meio de açóes denominadas requisitos de autocuidado, seguindo um modelo, e elas contribuem de maneira específica para a integridade, as funçôes e no desenvolvimento humano.

Na Teoria de Orem (McEWEN; WILLS, 2009) há três tipos de requisitos de autocuidado: os universais; os do desenvolvimento; e os do desvio da saúde. Os dois primeiros são inerentes à condição humana e o terceiro é circunstancial. Fragmentos do texto dos artigos que relacionam-se a essas concepçóes:

[...] deve-se atentar para os comprometimentos em suas funçôes cotidianas. (A1).

[...] o gerenciamento das condiçốes crônicas, como as doenças reumáticas, requer por parte do paciente uma mudança no estilo de vida e de comportamentos diários. (A1).

[...] o cuidado se constrói nas relações terapêuticas em que se considera o processo de saúde e doença como impactante na condição de vida do indivíduo. (A1).

[...] A importância da independência na rotina diária para o desenvolvimento integral da criança torna-se primordial. (A2).

[...] tudo que as pessoas fazem para ocupar-se, incluindo cuidarem de si mesmas [...] (A2).

[...] terapeutas ocupacionais - que têm interesse em pesquisas que tomam o desenvolvimento da criança como objeto de estudo, particularmente quando relacionadas ao autocuidado e à automanutenção, como o banho, [cuidar do] vestuário, alimentaçáo, uso do banheiro, higiene oral e comunicação. (A2).

$[\ldots]$ atividades costumeiras do dia a dia [...] (A3).

[...] cotidianeidad de las personas es decir, en las actividades de la vida diaria [...] (A6).

[...] após a ocorrência de uma lesão neurológica, o cliente tem uma habilidade limitada para se adaptar às novas circunstâncias e demandas encontradas durante a realização das atividades de seu cotidiano [...] (A8).

[...] necessidades de autocuidado acompanham os indivíduos durante toda a sua vida, sendo que algumas são geradas e modificadas pelo processo de envelhecimento [...] (A9).

[...] Las actividades de la vida diaria permiten el autocuidado [...] (A11).

Entretanto, observa-se que no Brasil a adoção da denominação atividades de vida diária para a área de desempenho, então denominada autocuidado, demorou a ser incorporada no discurso e na produção científica de terapeutas ocupacionais. E até 2008 encontram-se documentos em que os termos autocuidado e atividades de vida diária referem-se a atividades cotidianas voltadas para o próprio indivíduo, classificadas na área de desempenho AVD.

\subsubsection{Subcategoria $\mathrm{O}$ autocuidado e a socialização}

O homem é um ser social e necessita de outros no seu processo de sobrevivência. Implicitamente, na Teoria de Orem (1980), está a crença de que os seres humanos engajam-se em comunicação e intercâmbios contínuos, entre si e o ambiente, para a sua subsistência e funcionalidade. A autora destaca o funcionamento e o bem-estar humano; a promoção do funcionamento e desenvolvimento humano em grupos sociais, conforme o potencial humano; limitaçóes humanas conhecidas; e o desejo de ser normal. Nos artigos A1 e A6, os autores terapeutas ocupacionais aludem que o autocuidado responde ao objetivo de socialização do indivíduo, promovendo sua interaçáo com o meio e com outros que vivenciam as mesmas questôes de saúde, visando uma transformação.

[...] a força para a mudança provém dos próprios participantes do grupo, já que um integrante, ao se sentir motivado, fortalece o outro para que se engaje na busca de transformaçóes. (A1). 
[...] O grupo assiste e promove a mudança e, com o maior envolvimento e interesse do participante no grupo, podem ser observados aspectos como redução da dor, maior capacidade de enfrentar a doença, maior senso de competência durante a realização de atividades cotidianas, aumento de socialização [...] (A1).

[...] À medida que a criança adquire independência nas atividades próprias do cotidiano, supóe-se que seja capaz de participar em áreas sociais mais amplas com ou sem acompanhantes, vivenciando privilégios pessoais e sociais dessas situaçóes. (A2).

[...] Actividad de la Vida Diaria (AVD) analizada es la socialización [...] (A6).

\subsubsection{Subcategoria $O$ autocuidado e a autoimagem}

A imagem que o indivíduo tem de si mesmo influencia a sua relação intra e interpessoal, podendo favorecer, motivar as suas açôes ou limitar o seu desempenho. Os autores de A1 exemplificam e destacam o grupo como espaço de reflexão e percepção da autoimagem. Já os autores do artigo A11 associam o autocuidado do indivíduo e sua autonomia para agir de modo a contribuir para a melhoria de sua autoimagem. Nesse sentido, aduzem que Orem (1980) considera que o indivíduo é saudável quando consegue refletir sobre si mesmo e comunicar-se com os outros e, para tanto, é necessário uma autoimagem favorável.

[...] quando o coordenador do grupo e os próprios integrantes ouvem com sensibilidade cada componente e o ambiente torna-se seguro e confiável, os participantes revelam-se em um nível mais profundo, o que aumenta a possibilidade de se compreender e modificar a percepção de si próprio. (A1).

[...] mejorando la imagen que el individuo tiene de sí mismo y en su autonomía en cuanto a aspectos personales (alimentación, baño, vestuario, y otras) y sociales (manejo interno y externo) [...] (A11).

\subsection{Autonomia e independência para o autocuidado}

A autonomia associa-se ao poder de o indivíduo identificar as necessidades, fazer julgamentos necessários e agir deliberadamente para realizar o seu autocuidado (McEWEN; WILLS, 2009). Identifica-se a importância da autonomia do indivíduo frente ao processo saúde-doença e o favorecimento de sua capacidade de tomada de decisão e ação frente à problemática estabelecida. Sendo assim, o indivíduo pode responsabilizar-se pelo seu autocuidado.

\subsubsection{Subcategoria Conscientização, compreensão e a vivência do processo de saúde-doença pelo indivíduo}

Os autores revelam a importância da compreensão do próprio indivíduo acerca de sua condição de saúde ou doença, bem como de sua responsabilidade na manutenção saudável do seu próprio desempenho, o que é exemplificado nos trechos:

[...] destacando-se, em especial, o esforço dos indivíduos para modificar os hábitos de vida e a forma como realizam as atividades cotidianas [...] (A1).

[...] compreensão e a vivência dos processos de saúde-doença [...] (A3).

[...] toma de conciencia del individuo acerca de su situación de salud-enfermedad y que de esta manera logre comprender cual es su responsabilidad en la mantención de su calidad de vida [...] (A7).

[...] Que los participantes adquieran herramientas para el desarrollo de nuevos hábitos, en un contexto individual y familiar [...] (A7).

Orem (1980) afirma que a saúde humana é a capacidade de o indivíduo refletir sobre si mesmo, simbolizar a experiência bem como tomar decisóes e responsabilizar-se pelo autocuidado, envolvendo açóes para a sustentaçáo da vida e a regulação das funçôes.

\subsubsection{Subcategoria Autonomia sobre suas atividades cotidianas e hábitos de saúde}

Nos trechos de alguns artigos observa-se que o autocuidado implica autonomia do indivíduo em relação às atividades cotidianas e hábitos de saúde.

[...] o paciente tem papel ativo, central em seu tratamento [...] (A1). 
[...] ao auxiliar o indivíduo na mudança de comportamentos diários, os profissionais de saúde não só estariam lhe possibilitando realizar novas atividades mas propondo que esse sujeito pense em seu cotidiano, em seu significado e nos fatores limitantes para o desempenho das atividades de vida diárias e em sua capacidade de se adaptar. (A1).

[...] o desempenho nessas atividades parece ser realmente importante para que a criança seja capaz de satisfazer suas necessidades básicas, garantindo-lhe maior independência e participação no ambiente domiciliar [...] (A2).

[...] No que se refere à independência da criança na área de autocuidado, percebe-se que a assistência tipicamente oferecida pelo cuidador para o desempenho de tarefas da rotina diária é maior que a esperada [...] (A2).

[...] autonomía frente à su situación de salud en relación a la significancia personal de sus hábitos alimentarios [...] (A7).

[...] a administração do próprio cotidiano pelo indivíduo configura-se como prática de autocuidado. [...] (A9).

\subsubsection{Subcategoria Autonomia do indivíduo para comunicar aos profissionais de saúde questões relativas ao seu próprio processo de saúde-doença}

$\mathrm{O}$ autocuidado associa-se à capacidade de o indivíduo expressar à equipe não apenas necessidades mas também suas possibilidades para a realização do autocuidado. A capacidade de refletir e comunicar-se sobre si próprio, bem como acerca de sua experiência com o processo saúde-doença, são fundamentais para a saúde humana (McEWEN; WILLS, 2009). Nos artigos A1 e A3 encontram-se referências a essa questão:

[...] o cuidado ocorre a partir de uma interação entre dois ou mais sujeitos visando o alívio de um sofrimento ou o alcance do bem-estar, sempre mediada por saberes especificamente voltados para essa finalidade. (A1).

[...] Produzindo um ambiente onde os sujeitos do cuidado possam atuar de forma a se apropriarem de suas produçóes de saúde, fomentando diálogos entre a compreensão e a vivência dos processos de saúde-doença e as leituras dos profissionais de Saúde [...] (A3).

\subsubsection{Subcategoria A autonomia e sua relação com o ambiente}

A capacidade de o indivíduo realizar por si próprio o autocuidado é permeada por crenças, valores e hábitos e outros aspectos do contexto, conforme exemplificado nos artigos A1, A2 e A8.

[...] a dor crônica pode gerar dificuldades funcionais, afetivas, comportamentais e sociais, impactando na execução de atividades de vida diária. (A1).

[...] a criança melhora o seu desempenho funcional e a capacidade de autocuidado a partir do momento em que é levada a se envolver em atividades cada vez mais complexas, que fazem parte da vida diária. [...] (A2).

[...] o modo como o cliente realizará suas atividades, a necessidade de auxílio, a autonomia e a independência adquirida também sofrerão uma interferência da família, de seu modo de vida, de sua cultura e de seus hábitos [...] (A8).

Destaca-se, entretanto, que o conceito de independência, na perspectiva da Terapia Ocupacional, geralmente é associado à independência funcional, que é a habilidade de desempenhar uma determinada tarefa sem auxílio, indução ou supervisão (HAGEDORN, 2007). A independência funcional, portanto, é uma das metas do terapeuta ocupacional em sua relação profissional com o indíviduo/família e comunidade.

\subsection{Intervenção do terapeuta ocupacional para favorecer o autocuidado pelo indivíduo}

Segundo o artigo primeiro da resolução 316, de 19 de julho de 2006, do Conselho Federal de Fisioterapia e Terapia Ocupacional - COFFITO, que dispóe sobre a prática de Atividades de Vida Diária, de Atividades Instrumentais da Vida Diária e Tecnologia Assistiva pelo Terapeuta Ocupacional (CONSELHO..., 2006, p. 79):

É de exclusiva competência do Terapeuta Ocupacional, no âmbito de sua atuação, avaliar as habilidades funcionais do indivíduo, elaborar a programação terapêutico-ocupacional e executar o treinamento das funçóes para o desenvolvimento das capacidades de desempenho das Atividades de Vida Diária 
(AVDs) e Atividades Instrumentais de Vida Diária (AIVDs) para as áreas comprometidas no desempenho ocupacional, motor, sensorial, percepto-cognitivo, mental, emocional, comportamental, funcional, cultural, social e econômico de pacientes.

Terapeutas ocupacionais avaliam as áreas de desempenho a fim de identificar possíveis comprometimentos, bem como a competência com que as pessoas realizam as atividades em sua rotina diária. Mesmo diante de condições que limitem a capacidade do indivíduo na realização do autocuidado, ele pode realizá-lo com o auxílio de recursos, como adaptaçôes ou dispositivos facilitadores do desempenho, denominados Tecnologia Assistiva - TA. Esses recursos podem ser gradativamente retirados quando a funcionalidade for recuperada, ou permanecerem como adaptaçóes para o desempenho modificado. Considerando-se o conceito de competência para o autocuidado, depara-se com a necessidade de o indivíduo adaptar-se aos diferentes contextos e desenvolver mudanças, assimilando novos papéis e envolvendo-se com aqueles que estão no seu entorno, quer seja ele um sujeito cuidado ou um cuidador.

\subsubsection{Subcategoria Intervenções privativas do terapeuta ocupacional}

Destaca-se na prática profissional do terapeuta ocupacional o processo de avaliaçáo, compreendendo o desempenho do indivíduo e o contexto que o envolve, o que é evidenciado na maioria dos artigos analisados.

[...] o grupo configura-se em um espaço de cuidado, de reconhecimento das necessidades subjetivas e coletivas, ou seja, um grupo constrói o cuidado a partir do conceito de integralidade, com enfoque individual e coletivo. [...] (A1).

[...] O terapeuta ocupacional avalia e trata os déficits nos componentes de desempenho, focalizando a sua intervenção na identificação de alteraçôes possíveis no campo das habilidades funcionais que interferem na participação do indivíduo em atividades diárias em geral. [...] (A2).

[...] nesse leque de elementos que compóem as áreas de ocupação, as Atividades de Vida Diária (AVD) assumem um papel de extrema relevância no contexto terapêutico [...] (A2).
[...] cresce a importância da avaliação em Terapia Ocupacional e a atenção especial ao desempenho da criança na área das AVDs, como condição para conseguir prever ou reparar danos ao processo de desenvolvimento integral [...] (A2).

[...] Este estudo utilizou a escala de autocuidado das Partes I (habilidades funcionais) e II (assistência do cuidador) do teste proposto pelo PEDI [...] (A2).

[...] A partir do proposto no plano de tratamento, a intervenção objetivou o envolvimento da criança nas atividades de autocuidado, de modo que nas sessóes de terapia ocupacional foram favorecidas experiências nas tarefas de higiene, vestuário e alimentação [...] (A2).

[...] Considerando-se o conjunto de ganhos obtidos em relaçáo ao desempenho ocupacional da criança e ao nível de assistência do cuidador às atividades da área de autocuidado, após a intervenção dos profissionais e o treino de habilidades funcionais provavelmente foram criadas condiçôes mais favoráveis ao desenvolvimento integral da criança com PC [...] (A2).

[...] a ação da Terapia Ocupacional, nessas condiçôes, constitui-se em poder entender e intervir nas manifestações e descontinuidades da cotidianidade ocasionadas por situaçôes diversas de adoecimento, pelo próprio impacto dos processos saúde-doença nos contextos de vida dos sujeitos e pela hospitalização [...] (A3).

[...] Avaliar a percepção dos sujeitos acerca das limitaçôes em todas as áreas de ocupaçáo, em consequência da IRC e do tratamento hemodialítico [...] (A5).

[...] indivíduos com IRC podem sim, se necessário e com ajuda de profissionais, desenvolver rotina de afazeres, construir projetos e fazer algo que tenha significado para si, ou seja, reconstruir seu cotidiano [...] (A5).

[...] A abordagem do terapeuta ocupacional a portadores de dor crônica deve voltar-se para a superação da dor, estimulação e adoção de habilidades de autocuidado. [...] (A7).

[...] a adaptação aos déficits neurológicos interfere não apenas no cliente mas também na família, em sua rotina e em seus rituais 
cotidianos, alterando todo o modo de vida deles [...] (A8).

[...] o modo como o cliente realizará suas atividades, a necessidade de auxílio, a autonomia e a independência adquirida também sofrerão uma interferência da família, de seu modo de vida, de sua cultura e de seus hábitos [...] (A8).

[...] proporcionar à pessoa com demência estimulação cognitiva importante que possa levá-la à menor dependência nas atividades básicas e instrumentais da vida diária, tanto nos aspectos domésticos quanto sociais. [...] (A8).

[...] Mudanças comportamentais, ambientais e uso de dispositivos auxiliares incluem-se nessas práticas [...] (A9).

[...] Análises comparativas nas três áreas de desempenho funcional mostram diferenças significativas nas áreas de autocuidado e mobilidade [...] (A12).

\subsubsection{Subcategoria Como membro da equipe de Saúde}

Realizando açôes interdisciplinares na área da Saúde, o terapeuta ocupacional estimula o indivíduo a comunicar-se com a equipe acerca de seu próprio desempenho. Também, através de registros e instrumentos de avaliação, o terapeuta ocupacional disponibiliza à equipe sua percepção desse processo de autocuidado.

[...] Produzindo um ambiente onde os sujeitos do cuidado possam atuar de forma a se apropriarem de suas produçóes de saúde, fomentando diálogos entre a compreensáo e a vivência dos processos de saúde-doença e as leituras dos profissionais de Saúde [...] (A3).

[...] Para o idoso manter-se em seu meio com funcionalidade e autonomia é necessário que receba assistência interdisciplinar em todos os níveis de complexidade do Sistema Único de Saúde. [...] (A4).

[...] pode contribuir para a assistência deles assim como informaçóes para a enfermagem. [...] (A5).

\section{Considerações finais}

Neste estudo realizou-se uma análise sobre a concepção do autocuidado por terapeutas ocupacionais, o que foi possível mediante análise da produção científica nessa área. Três temas foram identificados a partir da análise temática do conteúdo dos artigos: o autocuidado e atividades de vida diária; autonomia e independência para o autocuidado; e a intervenção do terapeuta ocupacional para favorecer o autocuidado pelo indivíduo.

Os resultados evidenciam que apesar do termo autocuidado ser citado em todos os artigos, tal conceito é abordado pelos profissionais sob diferentes dimensôes, associado a atividades de vida diária como também articulado a atividades interdisciplinares com outros profissionais de Saúde.

No período de 1994 a 2002 existiu uma associação direta do termo autocuidado com atividades de vida diária, pois esse termo representava a área de desempenho que atualmente é denominada atividades da vida diária.

Pode-se considerar que o foco de pesquisa e intervenção de terapeutas ocupacionais - o desempenho humano - sugere que, em diferentes ciclos de vida, os indivíduos apresentam ou desenvolvem a autonomia frente às atividades de vida diária (AVDs), passando a ser dependentes em situaçóes de vulnerabilidade, como de doenças e de exclusão social. Porém esses indivíduos podem ser auxiliados por terapeutas ocupacionais em suas rotinas diárias, utilizando-se de adaptaçóes, modificaçóes, recursos de tecnologia assistiva e/ou reabilitação funcional. Os terapeutas ocupacionais promovem a independência funcional do indivíduo, favorecendo a sua autonomia, assim como a retomada de rotinas.

Contata-se também a importância do envolvimento do cuidador no processo de cuidado e promoção da autonomia, sob orientação e parcerias estabelecidas no processo terapêutico ocupacional.

A interação interdisciplinar favorece que os objetivos de um plano terapêutico sejam atingidos, promovendo assim a efetividade na atenção à população envolvida nesse processo, seja de adoecimento, seja de treino de habilidades e aquisiçóes para promover a independência e autonomia para o autocuidado.

Os referenciais de autocuidado tanto para a Terapia Ocupacional como para a Enfermagem aproximam-se nesse processo de cuidado e assistência, caracterizando a interdisciplinaridade, porém 
preservam-se as especificidades de cada profissão, e também geram motivação para o aprofundamento teórico e conceitual por meio de estudos, pesquisas e relatos de experiência que venham a caracterizar a importância do autocuidado para essas duas profissóes da área da Saúde.

Observam-se convergências entre as concepções dos autores dos artigos analisados com o conceito de autocuidado, sob o referencial da Teoria do Autocuidado de Orem (1971-2001). Infere-se que, de modo geral, os profissionais de Saúde auferirão benefícios da sistematização do conhecimento que fundamenta sua prática, utilizando-se do conhecimento já elaborado por outras áreas, quer da Saúde quer dos demais setores, porém levando em conta as respectivas especificidades, como seu objeto, finalidades e referenciais teórico-metodológicos.

\section{Referências}

AGNOLON, M. C.; SANTOS, S. S.; ALMEIDA, M. H. M. Grupo de orientação postural a idosos com dor osteomuscular: estabelecendo relaçóes entre teoria e prática. Revista de Terapia Ocupacional da USP, São Paulo, v. 17, n. 2, p. 80-86, maio/ago. 2006. http://dx.doi. org/10.11606/issn.2238-6149.v17i2p80-86

ALMEIDA, M. H. M. et al. Confiabilidade do Instrumento para Classificação de Idosos quanto à Capacidade para o Autocuidado. Revista de Saúde Pública, São Paulo, v. 42, n. 2, p. 317-23, 2008. http://dx.doi.org/10.1590/ S0034-89102008005000003

ALLEGRETTI, A. L. C.; MANCINI, M. C.; SCHWARTZMAN, J. S. Estudo do desempenho funcional de crianças com paralisia cerebral diparética espástica utilizando o Pediatric Evaluation of Disability Inventory (PEDI). Temas sobre Desenvolvimento, São Paulo, v. 11, n. 64, p. 5-11, set./out. 2002.

AMERICAN OCCUPATIONAL THERAPY ASSOCIATION - AOTA. Occupational Therapy Practice Framework: Domain and Process. American Journal Ocupational Therapy, New York, v. 56, p. 609-639, 2002. http://dx.doi.org/10.5014/ajot.56.6.609

AMERICAN OCCUPATIONAL THERAPY ASSOCIATION - AOTA. Uniform terminology for occupational therapy. American Journal Ocupational Therapy, New York, v. 48, p. 1047-1054, 1994. http:// dx.doi.org/10.5014/ajot.48.11.1047

BEZERRA, K. V.; SANTOS, J. L. F. O cotidiano de pessoas com insuficiência renal crônica em tratamento hemodialítico. Revista Latino-americana de Enfermagem, São Paulo, n. 16, v. 4, p. 686-691, jul./ago. 2008. http:// dx.doi.org/10.1590/S0104-11692008000400006

CONSELHO FEDERAL DE FISIOTERAPIA E TERAPIA OCUPACIONAL - COFFITO. Resolução no 316, de 19 de julho de 2006. Dispóe sobre a prática de Atividades de Vida Diária, de Atividades Instrumentais da Vida Diária e Tecnologia Assistiva pelo Terapeuta Ocupacional e dá outras providências. Diário Oficial da República Federativa do Brasil, Brasília, DF, 03 ago. 2006. Seção 1, n. 158, p. 79. Disponível em: <http:// www.coffito.org.br/>. Acesso em: 19 maio 2011.

CONTI, J. A interferência dos aspectos perceptocognitivos nas atividades de vida diária e nas atividades instrumentais de vida diária, em clientes com sequelas por lesão neurológica. Acta Fisiátrica, São Paulo, v. 13, n. 2, p. 83-86, ago. 2006.

FREITAS, R. C. O.; NIGRI, F. N. Terapia ocupacional: uma proposta de transformação do cotidiano de pessoas com demência. Reabilitar, São Paulo, v. 8, n. 31, p. 60-65. abr./jun. 2006.

GAlheigO, S. M.; ANGEli, A. A. C. Terapia ocupacional e o cuidado integral à saúde de crianças e adolescentes: a construção do Projeto ACCALANTO. Revista de Terapia Ocupacional da Universidade de São Paulo. São Paulo, v. 19, n. 3, p. 137-143, dez. 2008. http://dx.doi.org/10.11606/issn.2238-6149.v19i3p137-143 GANONG, L. H. Integrative reviews of nursing research. Research in Nursing \& Health, New York, v. 10, p. 1-11, 1987. PMid:3644366. http://dx.doi.org/10.1002/ nur. 4770100103

HAGEDORN, R. Ferramentas para a prática em terapia ocupacional: uma abordagem estruturada aos conhecimentos e processos centrais. São Paulo: Roca, 2007. p. 72-73.

HASSELKUS, B. R. Introducción a las poblaciones de adultos y ancianos. In: CREPEAU, E. B.; COHN, E. S.; SCHELL, B. A. B. (Orgs.). Willard \& Spackman: Terapia Ocupacional. Médica Panamericana, 2008, p. 757-766.

LABBÉ, M. E.; VALDÉS, G.; LÛER, S. K. Valoración del impacto funcional producido en participantes de taller laboral protegido. Revista Chilena de Terapia Ocupacional, Santiago, n. 5, p. 61-68, nov. 2005.

McEWEN M.; WILLS E. M. Bases teóricas para enfermagem. 2. ed. Traduçáo de Ana Maria Thorell. Porto Alegre: Artmed. 2009. p. 169-172.

MONTEIRO, J. A. et al. Avaliação do nível de independência nas atividades de vida diária da criança com paralisia cerebral: um estudo de caso. Cadernos de Terapia Ocupacional da UFSCar, São Carlos, v. 20, n. 1, p. 129-141, 2012. http://dx.doi.org/10.4322/cto.2012.014

OREM, D. E. Nursing: concepts of practice. 2. ed. New York: McGrau-Hill, 1980. chap. 3: Nursing and self-care, p. 35-54.

PORRAS, A. X. et al. Intervención de terapia ocupacional en prevención y tratamiento de obesidad y diabetes mellitus tipo II: nunca pensamos que era algo más que una dieta. Revista Chilena de Terapia Ocupacional, Santiago, v. 6, p. 55-68, nov. 2006. http://dx.doi. org/10.5354/0717-6767.2006.112

RUEDA, C. L. et al. Impacto en las áreas de desempeńo ocupacional como consecuencia de una fobia social. Revista 
Chilena de Terapia Ocupacional, Santiago, v. 7, p. 47-58, nov. 2007. http://dx.doi.org/10.5354/0717-6767.2007.78

TAVARES, A. A. et al. (Re) Organização do cotidiano de indivíduos com doenças crônicas. Cadernos de Terapia Ocupacional da UFSCar, São Carlos, v. 20, n. 1, p. 95-105, 2012. http://dx.doi.org/10.4322/cto.2012.011
TORRES, G. V.; DAVIM, R. M. B.; NÓBREGA, M. M. L. D. A. Aplicação do processo de enfermagem baseado na teoria de OREM: estudo de caso com uma adolescente grávida. Revista Latino-Americana de Enfermagem, Ribeirão Preto, v. 7, n. 2, p. 47-53, abr. 1999. http://dx.doi. org/10.1590/S0104-11691999000200007

\section{Contribuição dos Autores}

Regina Célia Titotto Castanharo: pesquisa bibliográfica nos bancos de dados, concepção do texto, seleção e análise dos artigos, redação e revisão do texto. Lillian Daisy Gonçalves Wolff: orientação e revisão do texto. 